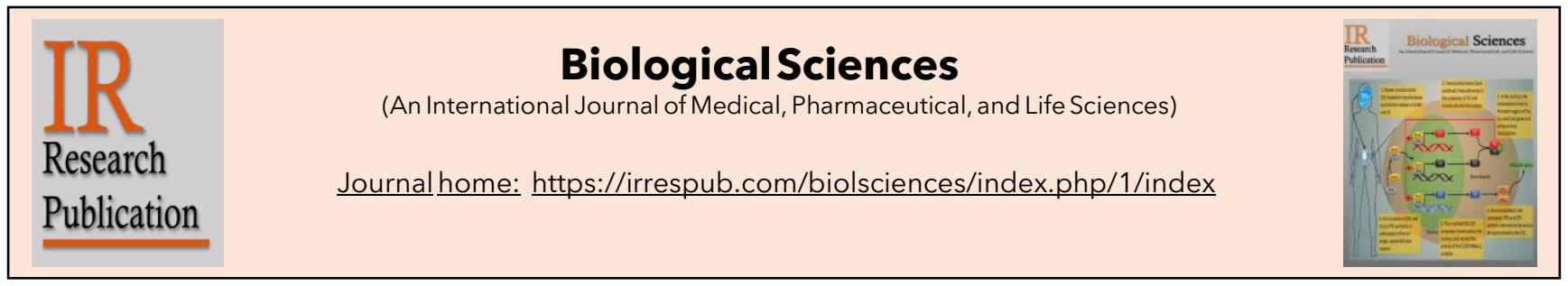

\title{
Paraquat poisoning: Death after oral intake
}

\author{
Sudhanshu Bansal*, Abhishek Kumar Gangwar, Sofia Thomas \\ Department of Pharmacy Practice, ISF College of Pharmacy, Moga, Punjab-142001, India.
}

\author{
ARTICLEHISTORY \\ Received: 15-01-2022 \\ Revised: 22-01-2022 \\ Accepted: 23-01-2022 \\ Online: 25-01-2022

\section{KEYWORDS} \\ Poisoning \\ Paraquat poisoning \\ Pesticide poisoning \\ Poisoning death
}

\section{ABSTRACT}

This case study describes an Indian male patient's death caused by paraquat after oral consumption. A 20 -year-old male patient attended the emergency department. He had a major complaint of stomach disorders, vomiting, fatigue, and hypothermia. It was confirmed that he was transferred from a nearby hospital after evaluating the situation. It was reported that paraquat poison had a systemic effect, and during the healing process, he was subject to multiple dialysis. This study will help doctors and clinicians to respond quickly to paraquat poisoning and aid in the early recovery and maintenance of poisoning.

\section{Introduction}

Paraquat is a poisonous herbicide that comes in a liquid form with a green tint and a strong odour that must be diluted before application. Paraquat herbicidal properties were first discovered in 1950, and it became commercially available in 1962. Paraquat is the second most commonly used weed killer in the market, with a high risk of side effects. In comparison to unintended consumption, most poisoning cases occur in adults due to suicide attempts. Pulmonary edema, convulsions, heart failure, renal failure, and hepatic failure are the most

\section{${ }^{*}$ Address for correspondence}

Department of Pharmacy Practice, ISF College of Pharmacy, Moga, Punjab-142001, India.

Email:sudhanshu.bansal98@gmail.com

DOI: http://dx.doi.org/10.55006/biolsciences.2022.2101 Published by IR Research Publication; Bansal S et al (c) 2022 by Biological Sciences is licensed under CC BY $\underline{4.0}$ frequent side effects of paraquat poisoning (1). The most frequent form of poisoning is oral consumption of paraquat. Death can result from lung injury or multiple organ failure. For diagnosis urine and plasma toxicity tests must be obtained. Hemoperfusion is the safest treatment in the early paraquat poisoning stages (2).

Paraquat poisoning can be classified into three categories-

1. Moderate poisoning:- $20 \mathrm{mg}$ paraquat ion per $\mathrm{kg}$ body weight) In which gastrointestinal effects are usually mild.

2. Extreme poisoning:- 20-40mg paraquat ion per kg of body weight) Patients with acute renal failure are said to be in this group. Acute lung injury and pulmonary fibrosis can occur concurrently. Death is estimated in 2 weeks.

3. Fulminant poisoning:- more than $40 \mathrm{mg}$ paraquat ion per $\mathrm{kg}$ body weight) multiple organ failure leading to death within a few hours or days (3). 


\section{Case presentation}

A 20-year-old patient was admitted into the emergency ward of Medanta S.N. Super speciality hospital with the symptoms of gastrointestinal disturbances, vomiting, and hypothermia with a history of poison intake. He was referred from the civil hospital Abohar Punjab, where he was diagnosed with poisoning a substance used as herbicide (paraquat). There was no previous history of convulsions, ENT bleeds, or loss of consciousness. The vital signs of the patient were recorded from day first to till death indicated in Table 1. On the other hand, systemic examination like the respiratory system was clear and cardiovascular system normal S1S2 with no murmur sound. In central nervous system GCS 15/15, pupils bilaterally equally responding to light, soft and nontender abdomen, his lips, nails, and fingertips were turned blue, and other observations can be seen in Table 2. In a previous hospital, he obtained gastric lavage and $\mathrm{KMnO} 4$. During dialysis on the same day, he was hemodynamically and neurologically stable. He was also given the antioxidant $\mathrm{N}$-acetyl cysteine and other supportive medications. Metabolic acidosis with hyperlactatemia was discovered during the investigation. The next day, the patient began to experience hypotension and oliguria. Due to worsening hemodynamic, he was intubated and put on mechanical ventilatory support. Another hemodialysis session was completed on the next day of admission. The patient had chronic hypotension, and he went into cardiac arrest at about 12:30 a.m. on the fourth day of admission. Cardiopulmonary resuscitation (CPR) was conducted and as per the Advanced Cardiac Life Support (ACLS) protocol; however, it was unable to resuscitate and declared dead.

\section{Investigations}

Paraquat poisoning was diagnosed, but no other abnormalities or deformities were discovered. His blood glucose and thyroid hormone levels were not predicted on the test. Another investigation, such as urine and chest $x$-ray, was considered fine. His family denied other examinations due to a lack of time and resources.

\section{Treatment}

There are currently no universally accepted treatment recommendations for paraquat poisoning. Mainly prevention of gastrointestinal absorption and increased elimination of paraquat from the blood, and alternative therapies such as immunotherapy and antioxidants are all options for treating paraquat ingestion. The strategies of prevention were as follow-

\section{Prevent gastrointestinal absorption}

Treatment with cathartics, activated charcoal, diatomaceous earths, and gastric lavage should be considered as an intervention in patients who present soon after ingestion to prevent absorption from the gastrointestinal tract. Gastric lavage accompanied by a dose of activated charcoal is the most common treatment, despite the evidence for the benefits of gastric lavage and charcoal being weak, with most research finding little benefit. Treatments to minimize paraquat absorption should be determined on a case-by-case basis, taking into account the possible amount of paraquat consumed as well as the time after ingestion. Early gastric lavage and charcoal treatment could have resulted in overall decreased plasma paraquat absorption and a better clinical outcome in our patients, but this is unclear.

\section{Elimination of poison from the blood}

Hemoperfusion (HP), Haemodialysis (HD), and Continuous Venovenous Hemofiltration (CVVH) can all be used to extract paraquat from the blood. It has been suggested that hemoperfusion, rather than hemodialysis, is a better way to extract paraquat from the blood. Using hemoperfusion within 12 hours of poisoning can reduce mortality. CVVH can improve survival, reduce the rate of organ dysfunction, and enable patients to receive additional treatments for a longer period of time. However, successful results were not consistently observed elsewhere whether hemodialysis or hemoperfusion is used alone or in combination. Despite this debate, it is prudent to begin an early trial of hemodialysis or hemoperfusion for 4 to 6 hours daily, understanding that care will be needed for at least 2 to 3 weeks, if available and after determining the likely amount of paraquat ingested.

\section{A variety of alternative therapies}

Several other treatments have been introduced for acute paraquat poisoning, including the use of the immuno-suppressant and antioxidant. The percentage of patients who received immune suppressant action (Cyclophosphamide, Metaphosphate, Vitamin E, and Vitamin C) had higher survival rates as compared to those who received it alone Without limiting the amount of oxygen. High concentrations of paraquat may further damage the body organism and lead to oxygen free radical species production. Although 
Table 1. Vitals of patient from day of admission till death.

\begin{tabular}{|l|c|c|c|c|}
\hline \multirow{2}{*}{ Day } & \multicolumn{3}{|c|}{ Vitals } \\
\cline { 2 - 5 } & $\begin{array}{c}\text { Blood } \\
\text { pressure(mmHg) }\end{array}$ & $\begin{array}{c}\text { Pulse } \\
\text { rate(beats/minute) }\end{array}$ & $\begin{array}{c}\text { Respiratory } \\
\text { rate(breath/minute) }\end{array}$ & Spo 2 \\
\hline First Day & $78 / 44$ & 40 & 20 & $96 \%$ \\
\hline Second Day & $75 / 44$ & 48 & 20 & $90 \%$ \\
\hline Third Day & $70 / 39$ & 36 & 18 & $84 \%$ \\
\hline Fourth Day & $67 / 35$ & 30 & 12 & $79 \%$ \\
\hline
\end{tabular}

Table 2. Laboratory observations.

\begin{tabular}{|l|c|c|c|c|c|}
\hline \multirow{2}{*}{ Parameter } & \multicolumn{4}{|c|}{ Observed Value } & \multirow{2}{*}{ Normal Range } \\
\cline { 2 - 5 } & First Day & $\begin{array}{c}\text { Second } \\
\text { Day }\end{array}$ & Third-Day & Fourth Day & \\
\hline Hemoglobin(male) & $10.6 \mathrm{~g} . \mathrm{dL}$ & $9.9 \mathrm{~g} . \mathrm{dL}$ & $9.1 \mathrm{~g} . \mathrm{dL}$ & $9.1 \mathrm{~g} \cdot \mathrm{dL}$ & $14-18 \mathrm{~g} / \mathrm{dL}$ \\
\hline Red blood cells & 2.18 & 2.0 & 2.1 & 2.1 & $\begin{array}{c}4.7- \\
6.1 \mathrm{cells} / \mathrm{mcL}\end{array}$ \\
\hline $\begin{array}{l}\text { Total Leukocyte } \\
\text { count }\end{array}$ & 13.26 & 18.26 & 19.86 & 19.86 & $4.5-11.0 \times 10^{9} / \mathrm{L}$ \\
\hline Neutrophils & $94.8 \%$ & $79.6 \%$ & $78.6 \%$ & $79.0 \%$ & $45-75 \%$ \\
\hline Platelets & 75000 & 72600 & 70300 & 68000 & $\begin{array}{c}1.5-4.0 \\
\text { Blood Urea }\end{array}$ \\
\hline Sr Uric Acid & $272.5 \mathrm{mg} / \mathrm{dL}$ & $288.5 \mathrm{mg} / \mathrm{dL}$ & $287.5 \mathrm{mg} / \mathrm{dL}$ & $298.5 \mathrm{mg} / \mathrm{dL}$ & $15-45 \mathrm{mg} / \mathrm{dL}$ \\
\hline SGOT & 4.5 & 4.0 & 4.2 & 4.2 & $2.4-7.0 \mathrm{mg} / \mathrm{dL}$ \\
\hline SGPT & 82.7 & 79.7 & 79.9 & 79.0 & $5-40 \mathrm{unit} / \mathrm{liter}$ \\
\hline Bilirubin Total & 115.1 & 122.3 & 132.3 & 133.9 & $7-56 \mathrm{unit} / \mathrm{liter}$ \\
\hline Haematocrit(male) & 37.9 & 1.82 & 1.99 & 1.99 & $0.3-1.2 \mathrm{mg} / \mathrm{dL}$ \\
\hline
\end{tabular}

Table 3. Treatment chat of patient.

\begin{tabular}{|c|c|c|c|c|c|}
\hline Date & $\begin{array}{l}\text { Brand } \\
\text { Name }\end{array}$ & Generic Name & $\begin{array}{c}\text { Route of } \\
\text { Administration }\end{array}$ & Frequency & Dose \\
\hline & Inj Dalacin & Clindamycin & $\mathrm{IV} / \mathrm{IM}$ & TDS & $600 \mathrm{mg}$ \\
\hline & $\begin{array}{c}\text { Inj } \\
\text { Meromac }\end{array}$ & Meropenem & $\mathrm{IV} / \mathrm{IM}$ & TDS & $500 \mathrm{mg}$ \\
\hline 18-9- & $\begin{array}{c}\operatorname{lnj} \\
\text { Pantocid }\end{array}$ & $\begin{array}{c}\text { Pantaprazole } \\
\text { sodium }\end{array}$ & $\mathrm{IV} / \mathrm{IM}$ & BDS & $40 \mathrm{mg}$ \\
\hline 2020 & Inj Emset & Ondansetron & $\mathrm{IV} / \mathrm{IM}$ & TDS & $4 \mathrm{mg}$ \\
\hline To & $\begin{array}{c}\text { Inj } \\
\text { Calcium } \\
\text { Gluconate }\end{array}$ & Calcium Gluconate & $\mathrm{IV} / \mathrm{IM}$ & TDS & $100 \mathrm{mg} / \mathrm{ml}$ \\
\hline & Inj KCL & Potassium Chloride & $\mathrm{IV} / \mathrm{IM}$ & STAT & $20 \mathrm{meq}$ \\
\hline $\begin{array}{l}\text { 20-9- } \\
2020\end{array}$ & $\begin{array}{c}\operatorname{lnj} \\
\text { Dexona }\end{array}$ & Dexamethasona & IV/IM & TDS & $8 \mathrm{mg}$ \\
\hline
\end{tabular}


the effectiveness of immunosuppressant therapy has been disputed. As for some, but not all antiinflammatory medications prevent the development of oxygen-radical. The mechanism by which this occurs is unclear. However, this decrease in antiradical agent production may increase paraquat absorption. There is insufficient data to support the use of Vitamin C or any other antioxidants such as deferoxamine (4). Treatment chart can be seen in Table 3.

\section{Outcome and follow-up}

Paraquat poisoning is an uncommon but deadly clinical manifestation. There are currently no universally accepted recommendations for treating paraquat poisoning patients. Although there is little evidence for successful treatment of paraquat toxicity, early treatment with gastric lavage, charcoal, or diatomaceous earths may be beneficial in reducing absorption. Hemoperfusion, hemodialysis can be used to reduce paraquat levels in the blood after they have been absorbed. Immunosuppressant and antioxidant therapies are two alternative therapies that may be used in the treatment of paraquat poisoning. The patient in our case was not able to achieve a better result. Vomiting and early gastric lavage/charcoal can reduce paraquat absorption.

\section{Discussion}

Vomiting was the most common symptom, followed by changes in sensorium, oral ulceration, dyspnea, and loose stools. Paraquat has renal and hepatic effects throughout the body. Failure, pulmonary edema and fibrosis, cardiac failure, shock, convulsions, and multi-organ failure are just some of the conditions that can occur.

\section{Learning points/take-home messages}

- The most common cause of death was a delay in admission to the hospital. Due to a lack of a complete medical history and the lack of diagnostic tests,

- Diagnosis may be difficult. In the previous hospital, the patient had already gone through various treatment protocols.

- The patient in this situation was going from hemodialysis daily, but due to multiple organ failures, we were unable to save him from this lethal poison.

- Finally, it is recommended that make every effort to get to the hospital as soon as possible.

\section{Patient's perspective and consent}

Not Applicable as the patient is dead

\section{Contribution of authors}

SB: Data collection, and SB, ST, and AKG: Major contributor in writing and drafting the manuscript.

\section{Acknowledgments}

The authors express their gratitude to Dr. Arun Kalra H.O.D Medicine, Medanta S.N Super-specialty Hospital for his great vision and support.

\section{Conflicts of interests}

The authors declare no potential conflicts of interest regarding the research, authorship, and/or publication of this article.

\section{References}

1. Saravu K, Sekhar S, Pai A, Barkur AS, Rajesh V, Earla JR. Paraquat - A deadly poison: Report of a case and review. Indian Journal of Critical Care Medicine. 2013 May;17(3):182-4.

2. Rao R, Bhat R, Pathadka S, Chenji SK, Dsouza S. Golden hours in severe paraquat poisoning-the role of early haemoperfusion therapy. Journal of Clinical and Diagnostic Research. 2017 Feb 1;11(2):OC06-8.

3. Agarwal R, Srinivas R, Aggarwal A N, Gupta $D$. Experience with paraquat poisoning in a respiratory intensive care unit in North India. Singapore Med Journal. 2006;47(12).

4. Sarah A, Mario G, Alice MB, Kristin BH, Anthony $\mathrm{G}$, Michelle $\mathrm{M}$, et al. Paraquat Poisoning: Survival after Oral Ingestion. Journal of Family Medicine and Disease Prevention. $2019 \mathrm{Jul}$ 20;5(4). 